\title{
METODOLOGIAS ATIVAS GAMIFICADAS - UM CASE FATENP
}

\section{GAMIFIED ACTIVE METHODOLOGIES - A FATENP CASE}

\author{
Walter F. Stodieck, M.Sc. ${ }^{1}$ \\ Daniel de Oliveira, M.Sc. ${ }^{2}$ \\ Carlos Hopfer Jr, Esp. ${ }^{3}$ \\ (1) Faculdade de Tecnologia Nova Palhoça - FATENP \\ e-mail: walter.stodieck@unigranrio.edu.br \\ (2) Faculdade de Tecnologia Nova Palhoça - FATENP \\ e-mail: daniel.oliveira@unigranrio.edu.br \\ (3) Faculdade de Tecnologia Nova Palhoça - FATENP \\ e-mail: carlos.junior@unigranrio.edu.br
}

Palavras-Chave: Metodologia Ativa, Gamificação, Ensino.

O conceito de metodologias ativas vem ganhando cada vez mais espaço dentro das instituições de ensino, o que somado com o conceito da gamificação, vem se tornando uma ferramenta poderosa como forma de recuperar o foco do aluno no que é essencial para o aprendizado, a busca pelo conhecimento. Dentro deste contexto, o presente artigo busca traçar um caminho sobre como ambos os métodos podem ser estudados e trabalhados em conjunto para a formação de sistemas gamificados voltados para a educação através de um estudo de caso realizado ao longo do segundo semestre de 2016 que buscou o entendimento do assunto através da elaboração de um método de ensino com a união dos conceitos apresentados.

Keywords: Active Methodologies, Gamification, Education.

The concept of active methodologies has been gaining more and more space within educational institutions, which, together with the concept of gamification, has become a powerful tool as a way to recover the student's focus on what is essential for learning, the search By knowledge. Within this context, the present article seeks to trace a way on how both methods can be studied and worked together for the formation of systems aimed at education through a case study carried out during the second semester of 2016 that sought the Understanding of the subject through the elaboration of a teaching method with the union of the presented concepts

\section{Introdução}

A sociedade vem se modernizando cada vez mais com os avanços das tecnologias e as instituições de ensino precisam estar preparadas para receber os alunos destas novas gerações, de forma que o motivem a querer permanecer em sala de aula, mais que isso, que queiram permanecer com o 


\section{$16^{\circ}$ \\ ERGODESIGN USIHC CINAHPA}

foco na aula apresentada. Em um cenário como o de hoje, onde todos tem acesso a um smartgadget com todo o conhecimento disponível na palma da mão, é necessário que o professor repense o seu papel como difusor do conhecimento, deixando de ser o seu guardião para se tornar mais um facilitador do caminho para os novos aprendizados.

Neste sentido, aparecem os conceitos das metodologias ativas de aprendizado e o da gamificação, conceitos que mudam o papel do aluno, que até então era visto como uma espécie de esponja que deveria apenas absorver o que lhe era repassado e agora assume um papel mais participativo, onde ele poderá correr atrás do conhecimento desejado e formar suas próprias críticas e conclusões a respeito do assunto, podendo aperfeiçoar seus métodos de aprendizado e participando de projetos que apoiem o seu desenvolvimento.

Este artigo busca estudar sobre o assunto tanto das metodologias ativas quanto da gamificação e como ambos podem vir a exercer um papel de mudança no status do sistema de ensino como estratégias motivacionais para manter o foco dos alunos no que está querendo se ensinar. Junto ao estudo dos conceitos, foi feito um estudo de caso a partir da observação da implantação de um sistema gamificado de ensino para o curso de jogos digitais da Faculdade de Tecnologia da Nova Palhoça (FATENP) baseado nos conceitos do aprender fazendo e da gamificação.

\section{Metodologia}

Seja na área acadêmica ou profissional, tem-se inserido diferentes formas de metodologias no intuito de normatizar e planejar o desenvolvimento de situações que necessitem de um encaminhamento visando um resultado final. Bonfim (1995), diz que metodologia trata da solução de questões ou problemas através de etapas planejadas em situações particulares e concretas, servindo como norteador do caminho percorrido desde a definição do propósito até a $16^{\circ}$ Ergodesign - Congresso Internacional de Ergonomia e Usabilidade de Interfaces Humano Tecnológica: Produto, Informações Ambientes Construídos e Transporte

$16^{\circ}$ USIHC - Congresso Internacional de Ergonomia e Usabilidade de Interfaces Humano Computador

CINAHPA | 2017 - Congresso Internacional de Ambientes Hipermídia para Aprendizagem. sua solução. Nesta mesma linha, Jesus, Cardoso e Souza (2010), afirmam: "os métodos são basicamente sistemas de organização de procedimentos para obtenção, confirmação ou validação de enunciados particulares".

“A utilização de métodos como instrumentos auxiliares de uma tarefa é algo tão antigo como o próprio trabalho do homem. Toda atividade racional segue, de modo explicito ou não, um procedimento lógico que permite alcançar um objetivo determinado. Mesmo as tarefas mais simples obedecem a uma rotina caracterizada por uma sequência de etapas: um agricultor, por exemplo, sabe que atividades são necessárias para plantar e colher um produto agrícola; um aluno de uma autoescola aprende o conjunto de operações necessárias para dirigir um automóvel, etc."(BONFIM, 1995.)

Os processos de metodologias vem então para facilitar a resolução de problemas os quais, sem a resolução de uma série de questões, dificilmente alcançariam uma solução adequada. Para Stodieck (2014), "isso não significa que, ao não se valer da utilização de processos metodológicos, o profissional deixará de obter um resultado, mas sim que, ao se valer da força e vantagens que encontram-se nestes processos o resultado torna-se mais seguro". Ainda para o autor, o profissional terá sim um resultado mais assertivo e que poderá demandar na sugestão de novas soluções que dificilmente seriam percebidas sem a definição de etapas de uma metodogia.

Percebe-se então que um método pode estimular a criatividade ao apresentar possíveis novas soluções a partir das etapas trabalhadas facilitando o trabalho do mesmo. Estes novos resultados podem acabar por trazer uma nova luz sob o olhar da própria metodologia, podendo adatpa-la conforme a necessidade de sua utilização, dando ao profissional a autonomia de desenvolver o método que melhor funcione para 


\section{$16^{\circ}$ \\ ERGODESIGN USIHC CINAHPA}

si, surgindo assim processos diferentes entre si, mas com o mesmo objetivo: que é o de atingir o resultado mais assertivo.

Sob o ponto de vista da cocriatividade, Stodieck (2014) ainda traz também a questão sobre a participação efetiva tanto de quem aplica a ferramenta como de quem a recebe, o que vem de encontro com a definição das metodologias ativas na educação que tiram o professor do cargo de detentor do conhecimento para um facilitador da informação, fazendo com que os alunos tenham um papel mais ativo em sala de aula:

\begin{abstract}
"Outro aspecto que deve ser analisado ao se propor um processo que busque soluções inovadoras, é a da participação efetiva de todos os stakeholders envolvidos no projeto durante todas as etapas do mesmo. Pois, além de se tornar um processo cocriativo, o que gerará caminhos que levam a soluções inovadoras, de acordo com Vianna et al. (2013), já que a participação colaborativa das pessoas agrega para o processo, uma visão interna da organização, de pessoas que possuem um envolvimento diário com o produto, podendo assim explanar ao longo do projeto, diversos pontos referentes ao mesmo." (STODIECK, 2014)
\end{abstract}

Trabalhar com metodologias cocriativas auxilia na identificação das suas necessidades tornando o processo mais assertivo na procura por resultados. A participação de todos ao longo das etapas, traz um novo olhar para o problema, analisando-o sob novas perspectivas. A participação ativa de todos fortalece o surgimento de novas visões e maneiras de trabalhar, reforçando a característica inovadora a ser desenvolvida durante todo o processo.

\section{Metodologias ativas}

Ao se tratar de metodologias ativas do ensino, muito se fala sobre o paradigma da metodologia $16^{\circ}$ Ergodesign - Congresso Internacional de Ergonomia e Usabilidade de Interfaces Humano Tecnológica: Produto, Informações Ambientes Construídos e Transporte

$16^{\circ}$ USIHC - Congresso Internacional de Ergonomia e Usabilidade de Interfaces Humano Computador

CINAHPA | 2017 - Congresso Internacional de Ambientes Hipermídia para Aprendizagem. tradicional onde o professor é o transmissor do conteúdo a ser ensinado e o estudante assume uma postura passiva de espectador, que recebe a informação tal qual ela é passada e a repassa adiante da mesma maneira como foi aprendido, reproduzindo o seu conteúdo ipsis litteris sem uma possível crítica ou reflexão do que foi aprendido.

Neste cenário é que surge a metodologia ativa, onde muda-se esta forma de ensino, dando um papel mais participativo ao estudante, ele agora não é mais apenas um receptor, mas sim um sujeito na construção do conhecimento, o que vem de acordo com o que Freire (2001) defende sobre os métodos de ensino quando diz que "Ensinar não é transferir conhecimento, mas criar as possibilidades para a sua produção ou a sua construção". Barbosa e Moura (2013), fortalecem o conceito ao afirmarem que a metodologia ativa diz respeito à interação do aluno com o assunto de estudo em questão:

"Assim, aprendizagem ativa ocorre
quando o aluno interage com o assunto
em estudo - ouvindo, falando,
perguntando, discutindo, fazendo e
ensinando - sendo estimulado a
construir o conhecimento ao invés de
recebê-lo de forma passiva do
professor. Em um ambiente de
aprendizagem ativa, o professor atua
como orientador, supervisor,
facilitador do processo de
aprendizagem, e não apenas como
fonte única de informação e
conhecimento." (BARBOSA;
MOURA, 2013)

Outra característica deste modelo é a do aprender fazendo, utilizando cenários reais do dia-a-dia para a produção do conhecimento, fazendo com que o aluno vivencie experiências reais na prática, não ficando apenas na teoria, estando preparado para a sua futura entrada no mercado de trabalho, motivando o discente, exercitando a sua liberdade e autonomia na realização de 


\section{$16^{\circ}$ \\ ERGODESIGN USIHC CINAHPA}

escolhas e tomadas de decisões (MITRE et al.2008).

"As metodologias ativas utilizam a problematização como estratégia de ensino-aprendizagem, com o objetivo de alcançar e motivar o discente, pois diante do problema, ele se detém, examina, reflete, relaciona a sua história e passa a ressignificar suas descobertas." (MITRE et al., 2008)

Os autores ainda sugerem que este processo de ensino/aprendizagem deve estar vinculado a cenários práticos presentes ao longo de toda a carreira do aluno, para que estes enfrentem sempre novos desafios buscando soluções inovadoras por base do processo de reflexão ação - reflexão.

Para Barbosa e Moura (2013), a metodologia ativa é uma estratégia de ensino eficaz comparada com os métodos tradicionais, independente do assunto abordado, pois os alunos conseguem assimilar um maior volume de conteúdo e retém a informação por mais tempo, tendo uma maior satisfação e prazer durante as aulas.

A aprendizagem se torna mais significativa com as metodologias ativas e os alunos que experienciam esse método acabam por adquirir uma maior confiança em suas decisões e na aplicação prática do conhecimento. Os alunos também acabam melhorando o relacionamento com os colegas, passam a se expressar melhor além de adquirir gosto para resolver problemas e vivenciam situações que requerem tomar decisões por conta própria, reforçando a autonomia no pensar e no atuar (BARBOSA; MOURA, 2013).

Ao se tratar as metodologias ativas como uma estratégia de ensino e que vem ganhando cada vez mais espaço nas salas de aula, torna-se interessante associar o processo com o conceito de gamificação, que apesar de ser um conceito mais recente, já vem sendo utilizado $16^{\circ}$ Ergodesign - Congresso Internacional de Ergonomia e Usabilidade de Interfaces Humano Tecnológica: Produto, Informações Ambientes Construídos e Transporte

$16^{\circ}$ USIHC - Congresso Internacional de Ergonomia e Usabilidade de Interfaces Humano Computador

CINAHPA | 2017 - Congresso Internacional de Ambientes Hipermídia para Aprendizagem. empiricamente por professores ao longo dos anos como estratégia de engajamento e forma de criar uma construção lúdica e motivacional de aprendizagem.

\section{Gamificação}

Quando se fala em gamificação, deve-se tomar um certo cuidado para não confundir o processo com o que é um jogo literalmente. Embora para alguns pesquisadores não há esta separação, podemos dizer que a gamificação diz respeito à utilização de elementos que se encontram em um jogo em outras áreas e ferramentas de conhecimento sem que para isso se tenha a criação de um jogo propriamente dito.

Ao se analisar um jogo, percebe-se que este tem um fator motivacional e agregador, o que pode se tornar uma ferramenta interessante para ser utilizada. Para Zichermann e Cunningham (2011), quando concentraram-se em três componentes (prazer, recompensas e tempo) os jogos tornaram-se uma ferramenta poderosa. Para os autores, os jogos conseguem fazer com que as pessoas ajam de forma surpreendente até para si mesmas.

As pessoas, de acordo com os autores, são motivadas a jogar por quatro razões. Elas podem ser vistas em conjunto, ou separadamente, como motivadores individuais, sendo eles: para domínio do assunto, relaxar, diversão e socialização.

"Levando em conta então, o fator motivacional dos jogos, a "gamificação" de uma metodologia torna-se um fator diferencial na sua aplicação, principalmente quando se trata de um processo cocriativo, onde diferentes pessoas, com gostos e atitudes diversificados, encontram-se inseridos em um processo com um objetivo comum. Adaptar uma metodologia para que ela tenha suas características semelhantes a um jogo, acaba por abranger os quatro fatores 


\section{$16^{\circ}$ \\ ERGODESIGN USIHC CINAHPA}

motivacionais que levam as pessoas a jogar um jogo, chegando a novos resultados sem terem de passar por um processo maçante e que pouco conhecem." (STODIECK, 2014)

A gamificação de um processo auxilia no armazenamento de informações a respeito da mesma ao longo do tempo, pelas suas regras e informações autocontidas. Quando muitas pessoas utilizam um método, com o tempo ele vai se desenvolvendo em algo diferente e a sua fonte original acaba se perdendo. (GRAY, BROWN e MACANUFO, 2012).

"Logo, como em um jogo, um processo metodológico geralmente possui um espaço com suas próprias regras, limites de tempo e espaço com um momento de início e outro de fim dentro daquele espaço, regras que definem como este deve ser procedido, artefatos que auxiliarão física e visualmente o desenvolvimento das etapas e uma meta a ser alcançada." (STODIECK, 2014)

Gamificar então diz respeito sobre se aproveitar das características intrínsecas dos jogos para aperfeiçoar o método deixando-o mais dinâmico.

\section{Gamificação na educação}

Com o crescimento do avanço tecnológico, as pessoas vão tendo cada vez mais acesso tanto a apetrechos tecnológicos, os smartgadgets, como a informação, que vem sendo disponibilizada tanto de forma gratuita quanto de forma paga na internet. Em sala de aula, o professor acaba ganhando novos concorrentes na tentativa de conquistar a atenção do aluno, que muitas vezes acaba hipnotizado pelas cores, movimentos e dinamismo como as informações são passadas pela rede.

Para isso, o docente deve estudar novas alternativas de repassar o conhecimento ao aluno, fora a forma tradicional de slides e quadro $16^{\circ}$ Ergodesign - Congresso Internacional de Ergonomia e Usabilidade de Interfaces Humano Tecnológica: Produto, Informações Ambientes Construídos e Transporte

$16^{\circ}$ USIHC - Congresso Internacional de Ergonomia e Usabilidade de Interfaces Humano Computador

CINAHPA | 2017 - Congresso Internacional de Ambientes Hipermídia para Aprendizagem. negro, criando um ambiente de interesse e motivação ao discente, trazendo para o seu lado o uso destes gadgets como ferramentas de auxílio no aprendizado ao invés de travar uma batalha perdida pela atenção dos alunos.

Neste sentido, criar um ambiente gamificado para o ensino vem de acordo com o que já vem sendo aplicado com as metodologias ativas, onde se cria um ambiente lúdico e motivador para o aprendizado. De acordo com Alves, Minho e Diniz (2014), "o próprio Ministério da Cultura já reconhece os games como um produto audiovisual, e o Ministério da Educação apoia o desenvolvimento de ambientes gamificados".

Ainda de acordo com os autores, uma das plataformas gamificadas criadas pelo Ministério da Educação, o geekiegames, cria através de desafios uma ferramenta de engajamento e preparo dos alunos do ensino médio para o Exame Nacional do Ensino Médio (ENEM), onde essa mesma plataforma consegue identificar as limitações de cada aluno e acompanhar os avanços feitos por eles nas áreas de avaliação do exame.

Esta plataforma não só obteve um resultado positivo por parte do Ministério, como também levantou a possibilidade de gamificar outras plataformas de exames para os estudantes. Nesta Perspectiva, projetos vêm sendo desenvolvidos para preparação não só dos alunos, como também dos professores utilizando ferramentas gamificadas como forma de estratégias educacionais.

"O Grupo de Pesquisa Comunidades Virtuais (GPCV), da Universidade do Estado da Bahia (UNEB), realiza ações que articulam o ensino, pesquisa, extensão e o desenvolvimento de ambientes interativos, especialmente games. Dentro dessa perspectiva, o GPCV vem realizando...processos de formação inicial e permanente para os professores da rede pública do estado da Bahia, a fim de que construam 


\section{$16^{\circ}$ \\ ERGODESIGN USIHC CINAHPA}

novos sentidos para cultura digital, especialmente os games." (ALVES; MINHO; DINIZ, 2014)

Percebe-se então que o uso de ferramentas tecnológicas associadas a elementos dos jogos, pode-se criar um ambiente de aprendizado poderoso que incentiva o aluno a enfrentar desafios, superar suas limitações e ainda adquirir novos conhecimentos através de atividades práticas tendo um aprendizado significativo e de forma lúdica.

\section{Disciplinas Gamificadas}

Unindo os conceitos de metodologias ativas e gamificação dentro da educação, o curso de Jogos Digitais da Faculdade de Tecnologia da Nova Palhoça (FATENP) lançou a proposta para alguns professores de tentar gamificar suas disciplinas como forma de conquistar o aluno e trazer um atrativo a mais para o curso, visto que seus professores teriam a expertise o suficiente para tal desafio, já que se trata de um curso voltado para a área de games.

A matéria de Modelagem e Animação 2D, foi uma das primeiras a tentar um processo de gamificação do aprendizado, visto que era uma matéria que não teve boas experiências em seus semestres anteriores exatamente pela forma como a aula e suas avaliações, que são de cunho prático, eram ministradas. Para aplicar as mudanças, a primeira coisa a ser feita era repensar a forma de como as aulas seriam apresentadas e quais as ferramentas poderiam servir de apoio para a transmissão do conhecimento, para que os alunos se sentissem novamente envolvidos com o conteúdo e a forma de aprender o mesmo.

"Com a tecnologia surgiu a oportunidade de novos recursos para diferentes públicos (JENSEN, 2012). As tecnologias vêm transformando as práticas educacionais, fazendo com que instituições de ensino e seus pro ssionais pensem e repensem a forma de $16^{\circ}$ Ergodesign - Congresso Internacional de Ergonomia e Usabilidade de Interfaces Humano Tecnológica: Produto, Informações Ambientes Construídos e Transporte

$16^{\circ}$ USIHC - Congresso Internacional de Ergonomia e Usabilidade de Interfaces Humano Computador

CINAHPA | 2017 - Congresso Internacional de Ambientes Hipermídia para Aprendizagem. ensinar. Provocam estímulos às novas posturas nos aprendizes, despertando a "curiosidade" pela busca da criação do seu conhecimento por meio de diferentes práticas e recursos. Considere-se aqui, que as tecnologias apoiadas em diferentes mídias, num futuro próximo, transformarão completamente o sistema educacional, seja esta a distância ou presencial, contribuindo para facilitar o processo de aprendizagem." (SILVA; SARTORI; CATAPAN, 2014)

Sendo assim, resolveu-se usar as redes sociais como forma de transmissão do que se estava sendo feito em sala de aula, na forma de desafios semanais onde os alunos e o professor deveriam criar um desenho seguindo um tema escolhido por um dos membros da sala. Então, toda semana no instagram, com a identificação

"\#Desafio_FATENP" era apresentado um desenho com o tema proposto para que todos pudessem ver e acompanhar o desenvolvimento dos participantes. Tal estratégia vem de encontro com o que Silva, Sartori e Catapan (2014) defendem que "elementos e estratégias de jogos...permitem observar a relação da gamificação e da aprendizagem com o objetivo maior de promover o engajamento dos aprendizes", visto que houve uma grande participação dos alunos ao longo do semestre com a exibição de seus desenhos na rede social.

Além disso, foi criado um protótipo rudimentar de um sistema de recompensa para os alunos onde além das avaliações, eles receberiam um "valor" para cada exercício entregue em sala de aula que poderia ser convertido ou por ponto extra ou por presença, caso ao final do semestre algum aluno precisasse recuperar pontuação em um destes dois elementos.

E finalizando o sistema de recompensas, ao final do semestre, o aluno que tivesse desenvolvido o melhor trabalho final, que seria avaliado de acordo com todas as competências adquiridas ao longo do semestre, receberia um prêmio especial, 


\section{$16^{\circ}$ \\ ERGODESIGN USIHC CINAHPA}

em uma parceria feita com uma loja de jogos ainda no início do semestre.

Pode-se perceber ao longo do semestre letivo o engajamento dos alunos e a vontade deles em melhorar o seu desempenho na disciplina, mostrando a constante evolução dos traços de cada um dos alunos. Ao final do semestre, de uma turma de 10 alunos, apenas 02 precisaram recorrer ao sistema de recompensa para suprir pontos e faltas, enquanto o restante da turma, buscou a melhoria do seu desempenho na busca pela recompensa final.

\section{Considerações finais}

Apesar de parecerem novidades, tanto as metodologias ativas quanto a gamificação são processos que já vem acontecendo ao longo dos tempos. Ao se unir às forças de ambos os métodos focando no aprendizado do estudante, ter-se-á um resultado surpreendente como estratégias de motivação e engajamento dos mesmos na busca pelo conhecimento. Isso somado ao surgimento de novos cursos de graduação, como o de jogos digitais, que já possui em seu DNA a gamificação e o "fazer aprendendo", faz com que a aplicação destes métodos em suas disciplinas seja algo natural e de forma que acrescente ao currículo do discente.

Desde a aplicação do protótipo de gamificação na disciplina de animação $2 \mathrm{~d}$ do curso de jogos digitais, foi-se percebendo um avanço e empenho dos alunos em superar os seus desafios, além de ocorrer um fortalecimento da turma como um todo na busca pelos resultados, onde um ajudava o outro com o que cada um aprendia ao longo do semestre. No sentido motivacional, o sistema de recompensas fez com que os alunos buscassem entender mais o funcionamento das dinâmicas aplicadas para que ao final do semestre, fosse decidido qual o melhor projeto realizado.

Apesar disso, mesmo tendo ocorrido um forte engajamento dos alunos na disciplina, percebeuse que este sistema ainda precisa de um balanceamento, para que tanto a recompensa $16^{\circ}$ Ergodesign - Congresso Internacional de Ergonomia e Usabilidade de Interfaces Humano Tecnológica: Produto, Informações Ambientes Construídos e Transporte

$16^{\circ}$ USIHC - Congresso Internacional de Ergonomia e Usabilidade de Interfaces Humano Computador

CINAHPA | 2017 - Congresso Internacional de Ambientes Hipermídia para Aprendizagem.

quanto o envolvimento dos alunos, não seja banalizado, perdendo assim o sentido da proposta e do aprendizado.

Percebeu-se também que a recompensa por si só, apesar de criar um engajamento da turma, tem um tempo limitado de duração, pois logo o interesse dos alunos acaba se voltando para outra coisa. Para que a atenção e o foco dos mesmos fique voltada para o ensino, notou-se que deve-se aliar a recompensa com outros elementos de gamificação, criando um espaço lúdico que fomente a busca por mais.

Finalizando, nota-se hoje, que mesmo com a necessidade deste novo balanceamento e aprimoramento do sistema gamificado, ele teve o seu sucesso comprovado pela turma em relação a outras disciplinas que ocorriam em paralelo mas focada nos processos tradicionais de aprendizado. Ao final da aplicação do protótipo, a turma se mostrou apta para novos desafios e dentro da própria faculdade já assumiu em conjunto novos projetos com foco em metodologias ativas para o desenvolvimento de jogos.

\section{Referencias:}

ALVES, Lynn Rosalina Gama; MINHO, Marcelle Rose da Silva; DINIZ, Marcelo Vera Cruz. Gamificação: Diálogos com a Educação. In: FADEL, Luciane Maria et al (Org.). Gamificação na Educação. São Paulo: Pimenta Cultural, 2014. Cap. 3. p. 74-97.

BARBOSA, Eduardo Fernandes; MOURA, Dácio Guimarães de. Metodologias Ativas de Aprendizagem na Educação Profissional e Tecnológica. B. Tec. Senac, Rio de Janeiro, v. 39, n. 2, p.48-67, ago. 2013.

BROOKFIELD, S. D. Understanding and facilitating adult learning. San Francisco: Jossey-Bass, Publishers, 1990. 
$16^{\circ}$ Ergodesign - Congresso Internacional de Ergonomia e Usabilidade de Interfaces Humano Tecnológica: Produto, Informações Ambientes Construídos e Transporte

$16^{\circ}$ USIHC - Congresso Internacional de Ergonomia e Usabilidade de Interfaces Humano Computador

CINAHPA | 2017 - Congresso Internacional de Ambientes Hipermídia para Aprendizagem.

CANDY, P. Self direction for lifelong learning: a comprehensive guide to theory and practice. San Francisco : Jossey-Bass, 1991.

CAVALCANTI, R. A. Andragogia: a aprendizagem de adultos. Revista de Clínica Cirúrgica da Paraíba, nr 6 ano 4, 1999.

CERVERO, R. M.; MILLER J. D.; DIMMOCK, $\mathrm{K}$. H. The formal \& informal learning activities of practicing engineers. Engineering Education. November, p. 112-114, 1986.

CRANTON, P. Professional development as transformative learning: new perspectives for teachers of adults. San Francisco: Jossey-Bass Publishers, 1996.

FADEL, Luciane Maria et al (Org.). Gamificação na Educação. São Paulo: Pimenta Cultural, 2014. 300 p.

FREIRE, P. Pedagogia do Oprimido. $17^{\mathrm{a}} \mathrm{ed}$. Rio de Janeiro: Paz e Terra, 1987.

FREIRE, P. Pedagogia da autonomia:saberes necessários à prática educativa. $19^{\mathrm{a}} \mathrm{ed}$. São Paulo: Paz e Terra, 2001. 165p.

GRAY, Dave; BROWN, Sunni; MACANUFO, James. Gamestorming: Jogos Corporativos para Mudar, Inovar e Quebrar Regras. Rio de Janeiro: Alta Books, 2012, 284p.

HOULE, Ciryl O. Continuing learning in the professions. San Francisco: Jossey-Bass, 1980.

HUIZINGA, Johann. Homo Ludens: A Study of the Play Element in Culture. Boston, Beacon Press, 1955. 446 p.

LEZANA, Á. G. R., \&amp; CAMILOTTI, L. Elementos para um Programa de Capacitação de Empreendedores. In: Primeiro Encontro Nacional de Empreendedores. Florianópolis: 320 $-326,1999$.
LUCENA, E. A. A aprendizagem profissional de gerentes-proprietário do setor de varejo de vestuário de Florianópolis. Tese. Universidade Federal de Santa Catarina, Florianópolis, 2001.

MERRIAN, S. Adult learning and theory building: a review. Adult Education Quarterly. v. 37, n. 4, summer, p. 187-198, 1987.

MERRIAM, S., CAFFARELLA, R. Learning in adulthood: a comprehensive guide. San Francisco: Jossey-Bass, 1999.

MEZIROW, J. Transformative dimensions of adult learning. San Francisco (USA): JosseyBass, 1991.

MEZIROW, J. Contemporary paradigms of learning. Adult Education Quartely, 46(3): 158173, 1996.

MITRE, Sandra Minardi et al. Metodologias ativas de ensino-aprendizagem na formação profissional em saúde: debates atuais. Ciência \& Saúde Coletiva, [s.l.], v. 13, p.2133-2144, dez. 2008. FapUNIFESP (SciELO). http://dx.doi.org/10.1590/s141381232008000900018 .

MORAES, L.V.S. A dinâmica da aprendizagem gerencial - $O$ caso do Hospital Moinhos de Vento. Dissertação de Mestrado, Universidade Federal de Santa Catarina, Florianópolis, 2005.

MORAN, J. M. A educação que desejamos: novos desafios e como chegar lá. 5 . ed. Campinas: Papirus, 2014.

SILVA, Andreza Regina Lopes da; SARTORI, Viviane; CATAPAN, Araci Hack. Gamificação: uma proposta de engajamento na educação corporativa. In: FADEL, Luciane Maria et al (Org.). Gamificação na Educação. São Paulo: Pimenta Cultural, 2014. Cap. 8. p. 192-226.

STODIECK, Walter Flores. Brand DNA

Toolkit: Aplicação do Design em uma 


\section{$16^{\circ}$}

ERGODESIGN USIHC CINAHPA $16^{\circ}$ Ergodesign - Congresso Internacional de Ergonomia e Usabilidade de Interfaces Humano Tecnológica: Produto, Informações Ambientes Construídos e Transporte

$16^{\circ}$ USIHC - Congresso Internacional de Ergonomia e Usabilidade de Interfaces Humano Computador

CINAHPA | 2017 - Congresso Internacional de Ambientes Hipermídia para Aprendizagem.

Metodologia de Branding. 2014. $177 \mathrm{f}$.

Dissertação (Mestrado) - Curso de Design, Egr,

Universidade Federal de Santa Catarina,

Florianópolis, 2014.

TOUGH, A. The adult's learning projects: a fresh approach to theory and practice in adult learning. $2^{a}$ edição. Ontario: Ontario Institute for Studies in Education, 1971.

WALL, M. L.; PRADO, M. L. ; CARRARO, T. E. . The experience of undergoing a Teaching Internship applying active methodologies.

Acta Paulista de Enfermagem, v. 21, p. 515-519, 2008.

ZICHERMANN, Gabe; CUNNINGHAM, Christopher. Gamification by Design:

Implemeting Game Mechanics in Web and

Mobile Apps. Sebstopol: O'reilly, 2011. 210 p. 